\title{
LETTER
}

\section{Efficiency of transmission-based precautions (TBPs) against SARS-CoV-2 501Y.V2 variant transmissibility in the ICU}

\author{
Frédérique Schortgen ${ }^{*}$ (D), Pascal Andujar ${ }^{2}$, Amine Si Ali ${ }^{3}$, Layla Yahyaoui ${ }^{4}$ and Mounira Smati-Lafarge ${ }^{5}$
}

(C) 2021 Springer-Verlag GmbH Germany, part of Springer Nature

\section{Dear Editor,}

The rapid spread of SARS-CoV-2 variants has raised widespread concerns about the efficiency of transmission-based precautions (TBPs) for healthcare workers (HCWs) protection [1, 2]. Increased transmissibility of the UK variant 20I/501Y.V1 (also known as VOC 202012/01, or B.1.1.7) lead the medical community to call on Public Health England for a wider use of FFP3 mask outside of procedures at risk for viral aerosolisation [3]. The $20 \mathrm{H} / 501 \mathrm{Y} . \mathrm{V} 2$ variant (formerly $20 \mathrm{C} / 501 \mathrm{Y} . \mathrm{V} 2$, or B.1.351 lineage), first reported in South Africa, is preliminarily estimated to be significantly more contagious, the risk of higher disease severity is undervalued. Awaiting more scientific information, HCWs in the intensive care units (ICUs) are faced to an increased fear to be contaminated.

On the 5th of January 2021, the first patient detected in France with 20H/501Y.V2 and requiring critical care was admitted in our ICU. She presented with acute respiratory distress syndrome (ARDS) and positive nasopharyngeal Cycle Threshold (CT) Real Time-PCR (23-27 depending on gene). Since she was back from the Republic of Mozambique 9 days earlier, the 20H/501Y. V2 variant was suspected and confirmed by sequencing. She was managed by high-flow nasal cannula oxygenation (HFNCO: $60 \mathrm{~L} / 70 \% \mathrm{FiO}_{2}$ ) and dexamethasone. She required intubation on day-2. RT-PCR on distal lung was 39 on day-11, she was successfully extubated on day13 and SARS-CoV-2 serology was positive on day-14.

\footnotetext{
*Correspondence: Frederique.schortgen@chicreteil.fr

1 Intensive Care Unit, Centre Hospitalier Intercommunal de Créteil, 40 avenue de Verdun, 94000 Créteil, France
}

Full author information is available at the end of the article
During the same period of time, the 20I/501Y.V1 variant was identified in another patient managed by HFNCO (50 L/50\%) for 2 days. At that time, patients with coronavirus disease 2019 (COVID-19) represented 50\% of admitted patients in our 14 ICU-beds.

Our single rooms are at negative pressure $(-4 \mathrm{~Pa}$ with air change rate of 5 per hour) without airlock for protective equipment removal. None is dedicated for COVID-patients. The uncertainties on the high risk of transmission lead us to assess the effectiveness of TBPs we are routinely applying (see Table 1 ) in accordance with national and international guidelines [2, 4]. No additional measure was applied for the management of the two cases. A SARS-CoV-2 RT-PCR was performed in 48 volunteers (i.e. $75 \%$ of the $67 \mathrm{HCWs}$ who worked at least 1 day during patient stay) between day 7 and day 10 after last exposure. Screening encompassed 10/15 HCWs in charge of the 20H/501Y.V2 case and 5/8 in charge of the 20I/501Y.V1 case. Only one HCW, with SARS-COV-2 family contact, but not being in charge of cases, was found to be positive; neither 20H/501Y. V2 nor 20I/501Y.V1 variant was detected by sequencing. The absence of $\mathrm{HCW}$ contamination must be interpreted in light of available rooms at negative pressure and of measure compliance. We did not assess measures compliance; however, indirect markers suggest good application. Since March 2020, we have admitted 153 COVID-patients, $7 \mathrm{HCW}$ sere punctually detected positive for SARS-COV-2, of whom only one was suspected to be hospital-acquired. After the first wave of crisis in June, screening for SARS-CoV-2-specific antibodies in asymptomatic HCWs showed that no additional HCW had been contaminated. 


\section{Table 1 Characteristic and organisation of our 14 ICU-beds}

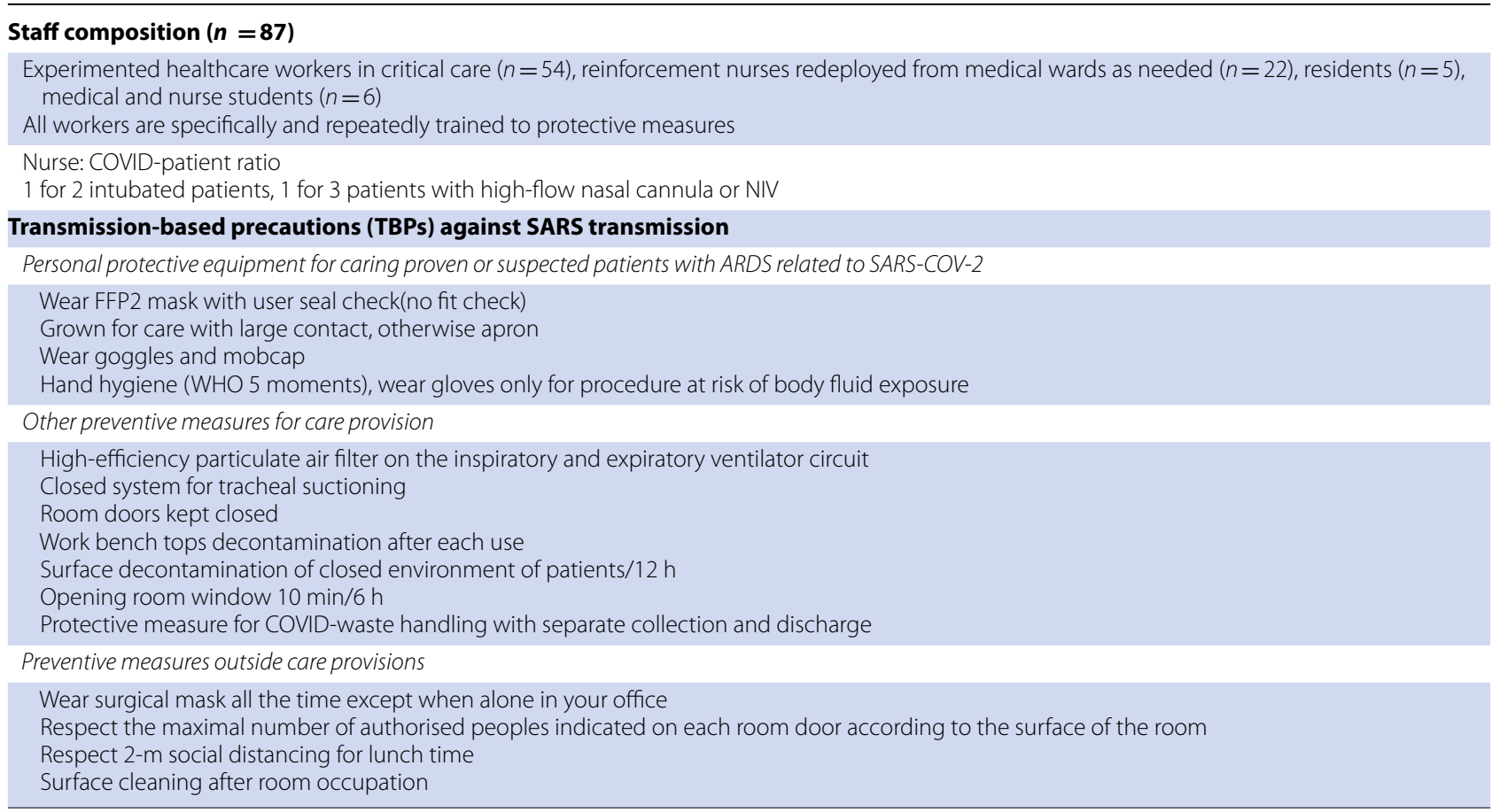

Despite a non-comprehensive screening test of exposed HCWs, our experience is reassuring for the efficiency of TBPs to prevent spreading of new SARS-COV-2 variants with increased transmissibility, even when performing manoeuvres at high risk of aerosolization. Our results cannot be transposed outside the ICU.

\footnotetext{
Author details

${ }^{1}$ Intensive Care Unit, Centre Hospitalier Intercommunal de Créteil, 40 avenue de Verdun, 94000 Créteil, France. ${ }^{2}$ Department of Occupational and Environmental Medicine, Centre Hospitalier Intercommunal de Créteil, Créteil, France. ${ }^{3}$ Infectious Disease Control and Prevention Unit, Centre Hospitalier Intercommunal de Créteil, Créteil, France. ${ }^{4}$ Emergency Department, Centre Hospitalier Intercommunal de Créteil, Créteil, France. ${ }^{5}$ Laboratory of Medical Biology, Centre Hospitalier Intercommunal de Créteil, Créteil, France.
}

\section{Declarations}

\section{Conflicts of interest}

Authors have no conflict of interest to declare.

\section{Publisher's Note}

Springer Nature remains neutral with regard to jurisdictional claims in published maps and institutional affiliations.

Received: 2 February 2021 Accepted: 4 March 2021

Published online: 18 March 2021

\section{References}

1. https://www.ecdc.europa.eu/sites/default/files/documents/COVID-19risk-related-to-spread-of-new-SARS-CoV-2-variants-EU-EEA-first-update. pdf. Accessed on 02 Feb 2021

2. https://www.cdc.gov/coronavirus/2019-ncov/transmission/variant.html. Accessed on 02 Feb 2021

3. https://www.bmj.com/content/372/bmj.n146. Accessed on 02 Feb 2021

4. https://www.sf2h.net/wp-content/uploads/2021/01/Avis-SF2H-du-17janvier-2021-relatif-a-la-PEC-patient-COVID-19.pdf. Accessed on 02 Feb 2021 